Portland State University

PDXScholar

Political Science Faculty Publications and

Presentations

Political Science

7-1-2021

\title{
Poor People's Beliefs and the Dynamics of Clientelism
}

\author{
Miquel Pellicer \\ Maynooth University \\ Eva Wegner \\ University of Marburg \\ Lindsay J. Benstead \\ Portland State University, benstead@pdx.edu \\ Ellen Lust \\ University of Gothenburg
}

Follow this and additional works at: https://pdxscholar.library.pdx.edu/polisci_fac

Part of the Political Science Commons

Let us know how access to this document benefits you.

\section{Citation Details}

Pellicer, M., Wegner, E., Benstead, L. J., \& Lust, E. (2021). Poor people's beliefs and the dynamics of clientelism. Journal of Theoretical Politics, 33(3), 300-332. https://doi.org/10.1177/09516298211003661

This Article is brought to you for free and open access. It has been accepted for inclusion in Political Science Faculty Publications and Presentations by an authorized administrator of PDXScholar. Please contact us if we can make this document more accessible: pdxscholar@pdx.edu. 
Journal of Theoretical Politics 2021, Vol. 33(3) 300-332 (C)The Author(s) 2021 dynamics of clientelism

Article reuse guidelines: sagepub.com/journals-permissions DOI: $10.1177 / 0951629821100366 \mid$ journals.sagepub.com/home/jtp

(SAGE

\title{
Miquel Pellicer
}

Department of Economics, Maynooth University, Ireland

\section{Eva Wegner}

Institute of Political Science, University of Marburg, Germany

\section{Lindsay J. Benstead}

Department of Political Science, Portland State University, Portland, OR, USA

\section{Ellen Lust}

Department of Political Science, University of Gothenburg, Sweden

\begin{abstract}
Why do some poor people engage in clientelism whereas others do not? Why does clientelism sometimes take traditional forms and sometimes more instrumental forms? We propose a formal model of clientelism that addresses these questions focusing primarily on the citizen's perspective. Citizens choose between supporting broad-based redistribution or engaging in clientelism. Introducing insights from social psychology, we study the interactions between citizen beliefs and values, and their political choices. Clientelism, political inefficacy, and inequality legitimation beliefs reinforce each other leading to multiple equilibria. One of these resembles traditional clientelism, with disempowered clients that legitimize social inequalities. Community connectivity breaks this reinforcement mechanism and leads to another equilibrium where clientelism takes a modern, instrumental, form. The model delivers insights on the role of citizen beliefs for their bargaining power as well as for the persistence and transformation of clientelism. We illustrate the key mechanisms with ethnographic literature on the topic.
\end{abstract}

\section{Corresponding author:}

Miquel Pellicer, Department of Economics, Maynooth University, Co. Kildare, Ireland.

Email: pellicer.miquel@gmail.com 


\section{Keywords}

Clientelism; Redistribution; System Justification; Political Efficacy

\section{Introduction}

The last few decades brought a wealth of new insights on the nature, mechanics, and drivers of clientelism. We have learned a great deal about party strategies (e.g., whether to target swing or core voters) and the mechanics of the exchange (e.g., the role of monitoring, reciprocity, and brokers). The literature made particular strides in understanding vote-buying, which it has come to view often as synonymous with clientelism. ${ }^{1}$ We have learned far less about why voters engage in clientelism. The calculations of voters have remained relatively simplified, mostly involving a simple trade-off between material benefits from clientelism and expressive benefits from voting for a programmatic alternative. The key result is that poorer individuals tend to sell their votes because their marginal utility of material benefits offered for their votes is higher (see Dixit and Londregan, 1996; Stokes et al., 2013). Variation in the poor's engagement in clientelism is mostly explained as the result of differences in party targeting (e.g., Finan and Schechter, 2012; Gans-Morse et al., 2014; Stokes, 2005)

The current emphasis on the supply side of the vote-buying variety of clientelism has left two significant gaps in our understanding. First, the political choices of the poor remain inadequately understood. Although clientelism indeed correlates with poverty (Brusco et al., 2004; Justesen and Manzetti, 2017; Stokes et al., 2013) and the mechanism in the literature explaining this correlation is compelling, poor individuals often purposefully establish political linkages other than clientelistic ones. A relevant literature on demand for redistribution argues that the poor ought to support political platforms promising income redistribution, precisely because their low income implies that they stand to gain the most from it (Alesina and Giuliano, 2011; Alesina and La Ferrara, 2005; Meltzer and Richard, 1981). The apparent contradictory conclusions of these two strands of literature suggest that factors in addition to income may matter for the poor's political choices. Second, the focus on vote-buying (or one-shot, material exchanges for votes) fails to shed light on the variation in forms of clientelism. As evidenced by classical literature on the topic (see the articles in Schmidt et al. (1977)), and increasingly acknowledged by current research (e.g., Hilgers, 2009; Lawson and Greene, 2014; Nichter, 2014, 2018; Pellicer et al., 2020), clientelism not only exists in its one-shot election-time instrumental form, but also in forms involving long-standing relations of insurance and support. These 'traditional' or 'relational' forms of clientelism may include affective ties and are embedded in social norms and personal relationships. Importantly, this type of clientelistic relationship is not a phenomenon of the past, but often still forms the backbone of modern, machine-style clientelistic organizations at the local level or organizes votes for candidates in the absence of such machines (Gottlieb, 2017; Lemarchand, 1972). Reaching a more complete understanding of clientelism requires considering both forms of exchanges. 
Following these observations, this paper seeks to address two core questions. First, what factors other than income drive the choice between clientelism and redistribution? Second, under which circumstances do the poor engage in traditional forms of clientelism, socially embedded, hierarchical, personal, and longterm, rather than in modern, essentially vote-buying, types?

We argue that broadening the theoretical framework of clientelism choice can yield insights into the two questions posed here. We propose to broaden this focus by integrating recent research from social psychology, and in particular on the legitimation of inequality. Prominent theories in social psychology such as 'belief in a just world' or 'system justification' argue that it can be psychologically adaptive in certain contexts to legitimize inequality (Jost et al., 2004; Lerner, 1982). Social psychology work on collective action argues that inequality delegitimation is one of the key psychological prerequisites of horizontal mobilization (Jost et al., 2012; Van Zomeren et al., 2008)). These insights have already expanded our understanding of demand for redistribution beyond material determinants (Alesina and Giuliano, 2011; Benabou and Tirole, 2006). Integrating inequality legitimation into the study of clientelism can also help understanding why some poor people engage in clientelism and others do not, and why some engage in traditional versus modern types of clientelism.

This article proposes a model that incorporates recent social psychology work on inequality legitimation to the study of clientelism. The model has the following key features. First, citizens choose whether to engage in clientelism or support a redistributive platform. Second, citizens hold efficacy perceptions concerning the chances of success of the redistributive platform, and perceptions on the legitimacy of inequality. Third, efficacy perceptions and inequality legitimation values are endogenously determined and interact with clientelism choices to generate different types of equilibria.

The model delivers three equilibria. One equilibrium features a high degree of inequality legitimation, low perceptions of efficacy, and widespread clientelism, the characteristics of traditional clientelism. A second equilibrium features the opposite characteristics, with the poor strongly condemning inequality and supporting the redistributive platform.

The key mechanism generating these equilibria is the complementarity between the extent of clientelism, perceptions of inefficacy, and legitimation of inequality. Perceptions of inefficacy induce citizens to believe that inequality is inevitable; facing this prospect they adapt psychologically by legitimizing inequality. Legitimizing inequality, in turn, leads them to better tolerate clientelism, leading to more clientelism, more inefficacy, and even more inequality legitimation.

These complementarities, however, can break down when communities become more informationally connected. This leads to a third equilibrium where clientelism and support for redistribution co-exist. Crucially, inequality in this equilibrium is not legitimized by the poor, in contrast to the traditional clientelism equilibrium. Clientelistic exchanges in this form can be considered more instrumental from the citizen's perspective, corresponding to vote-buying or modern clientelism. 
The results of the model emphasize the role of clients and their beliefs for the characteristics and dynamics of clientelism. First, the fact that clients in traditional settings legitimize inequality decreases their bargaining power and leads them to get a worse deal out of clientelism than in modern settings. Second, and related, the legitimation of inequality in traditional clientelism also makes it resilient and stable, requiring massive alterations of the environment in order for it to be eliminated. However, both the legitimation of inequality and the traditional form of clientelism that it supports can be gradually eroded. This can occur with increasing informational connectivity of the community, leading to a transformation of clientelism into a modern type. We illustrate the model's core insights with work from the ethnographic literature.

Our insights complement existing work on the role of supply factors for the bargaining power of clients (Corstange, 2018; Hilgers, 2009; Shami, 2012). We also contribute to an ongoing debate about the factors driving the persistence and decline of clientelism. So far, studies emphasize socio-economic or institutional factors and focus on the transformation of clientelistic into platform-driven, programmatic, politics (Bustikova and Corduneanu-Huci, 2017; Kitschelt and Kselman, 2013; Stokes et al., 2013). Our paper considers a potential transformation of traditional-style into electoral clientelism in addition to programmatic politics and shows how client beliefs affects these pathways. Our focus on the agency of clients and the important role clients play for the persistence of different types of clientelism links with an important nascent body of work in political science that puts the perspective of the citizen center stage (Kramon, 2016; Nichter, 2018; Nichter and Peress, 2017).

More generally, our model adds to the important growing literature that emphasizes the endogenous determination of values and perceptions of citizens for understanding political choice and political outcomes (Acharya et al., 2018; Minozzi, 2013). In our model, it is precisely the feedbacks between political choices and perceptions that drives our key insights on different types of clientelism. The psychological complementarity that underlies our results, between inefficacy and inequality legitimation, has received support in recent experimental work in social psychology and economics (Johnson and Fujita, 2012; Kay and Friesen, 2011; Pellicer et al., 2018; Van der Toorn et al., 2015).

The model also has important limitations. In particular, our aim to bring detail to the political choices and perceptions of the poor leads us to make simplifying assumptions which are needed to keep the model tractable. First, the model considers the supply side only in an extremely simplified way: we consider that there is a patron that chooses the level of clientelistic transfers, but the choice of the patron is modeled in the simplest possible way. The model does not consider politicians competing in elections. This implies, among other things, that we do not consider the credibility problems often addressed in clientelism models (Gallego, 2015; Keefer and Vlaicu, 2008; Robinson and Verdier, 2013; Stokes, 2005). The model is best thought of as representing informal political mobilization rather than formal voting, i.e., a model about grassroots mobilization in the pursuit of broad-based redistribution. Second, the model focuses particularly on poor individuals that 
stand to gain from redistribution; this implies that the model is best thought of as describing a community with high levels of inequality where the overwhelming majority of citizens are relatively poor. Third, the political choice we consider for the poor is a stark one between engaging in clientelism and supporting full redistribution. A priori this could appear to restrict its applicability to situations where there is a credible redistributive party, a situation not present in many developing countries. However, our interpretation of the model in terms of community mobilization renders it more widely applicable. The ethnographic literature provides ample evidence that a key trade-off faced by prospective clients in a variety of settings is between clientelistic benefits and horizontal grassroots organizations (e.g., Fernández et al., 2017; Holzner, 2004; Mitlin and Mogaladi, 2013; Rutten, 2007; Svampa and Pereyra, 2009).

\section{Static model of clientelism}

\section{I. Set-up}

General set-up. We consider a society of citizens (indexed by $i$ and distributed in the unit interval) all born with the same income: $y$. There is also a rich patron with income such that average income in the society is $\bar{y}^{2}$

The main decision that citizens take is between engaging in a clientelistic relationship with the rich patron or supporting a redistributive platform. The redistributive platform might achieve a given level of income redistribution (yielding $\bar{y}$ to everyone), but only with some probability $P$. Engaging in a clientelistic relation with the patron provides citizens with a transfer $T$, given by the patron.

Each citizen holds an individual belief regarding $P$, the probability of success of the redistribution platform. We denote this individual belief $p^{i} .^{3}$ Following social psychology literature, we refer to $p^{i}$ as individual $i$ 's efficacy beliefs. We assume that individuals are born with a benchmark efficacy level $p$, which is common to all citizens. As citizens go through life efficacy perceptions move away from this benchmark according to the realization of a random variable $\epsilon^{i}: p^{i}=p+\epsilon^{i}$. For simplicity, we assume that $\epsilon^{i}$ follows a uniform distribution with mean zero and extremes $\pm \sigma$, where $\sigma$ thus denotes the extent of diversity of opinion regarding efficacy.

Citizens care about their income as well as about inequality and its legitimacy. We denote individual beliefs on how much inequality is delegitimized by $\theta^{i}$. A key innovation of the model is that, following social psychology literature, we allow citizens to partly choose the degree of inequality delegitimation beliefs.

The timing of the model is as follows. First, individuals are born with benchmark efficacy $p$. Second, individuals choose inequality delegitimation $\theta^{i}$ and at the same time the patron chooses clientelistic transfers $T{ }^{4}$ Third, the idiosyncratic efficacy shock $\epsilon^{i}$ is realized. Fourth, citizens decide whether to engage in clientelism or support the redistributive platform. Finally, redistribution and transfers take place as appropriate and players die. 
We assume that the actual probability of redistribution $P$ equals the share of citizens choosing redistribution over clientelism: the more citizens support redistribution, the more likely it is to succeed. The level of clientelism in the community is the share of citizens choosing clientelism over redistribution and we denote it as $C$. Therefore, by construction, $C=1-P$.

Utility and choices. We assume that citizen's utility depends on their income, and on their views of inequality and its legitimacy. We capture inequality by the difference between mean income and citizen's income $(\bar{y}-y)$. If an individual decides to engage in clientelism, her utility is

$$
V_{C}^{i}=p^{i} \bar{y}+\left(1-p^{i}\right)(y+T)+\theta^{i}(\bar{y}-y)\left[\alpha-\left(1-p^{i}\right)\right]
$$

The first two terms are the utility from net income, which we assume as linear for simplicity. Even if the individual chooses clientelism, successful redistribution might still occur, with perceived probability $p^{i}$. So net income equals average income $\bar{y}$ with subjective probability $p^{i}$ and income $y$ plus clientelistic transfers $T$ otherwise.

The second term is the utility consequences of inequality. A key innovation of the model is the manner we introduce these consequences. Typically, inequality is introduced directly in the utility function as inequality aversion. It is considered that inequality generates disutility to the individual, and the strength of aversion depends among others on how legitimate the income distribution is viewed (Alesina and Giuliano, 2011). This corresponds to $\theta^{i}(\bar{y}-y)$ in the equation, where $\theta^{i}$ captures the strength of inequality delegitimation, and would typically enter the utility function with a negative sign.

The social psychology literature, however, provides a more nuanced account that focuses on the self-esteem consequences of legitimizing or delegitimizing inequality. In a synthesis of social psychology theories, Major and Schmader (2001) argue that perceiving inequality as illegitimate can be protective in the short run, but is harmful if sustained "chronically. ${ }^{5} \mathrm{We}$ model this in the simplest possible way by considering that viewing inequality as illegitimate (high $\theta^{i}(\bar{y}-y)$ ) has a positive and a negative psychological effect, which correspond to $\left[\alpha-\left(1-p^{i}\right)\right]$ in the equation. The parameter $\alpha<1$ captures the initial positive self-esteem effect of considering inequality as illegitimate. The term $1-p^{i}$ captures the negative effect, which accrues when one views inequality as illegitimate throughout one's whole life; this applies only in case there actually is inequality, i.e., if the redistributive platform does not succeed, with perceived probability $1-p^{i}$.

We now consider citizen's utility when supporting the redistributive platform. We assume that if an individual chooses to support the redistributive platform, she believes that her choice increases the chances of redistribution from $p^{i}$ to $p^{i}+g$. The parameter $g$ can be thought of as group identification in the social psychology literature. The idea is that having a high sense of group identification makes people take the perspective of the group instead of the individual when considering the implications of their actions. This leads them to consider that their choice has more impact for the success of the redistribution platform. The exact value of parameter 
$g$ and its interpretation in terms of group identification is not key to the model. What is crucial is that $g$ is higher than zero so that the individual perceives that her support of the redistributive platform makes it more likely to succeed. We generally think of $g$ as having a small value.

Citizens' utility in case of supporting the redistributive platform is, thus,

$$
V_{R}^{i}=\left(p^{i}+g\right) \bar{y}+\left(1-p^{i}-g\right) y+\theta^{i}(\bar{y}-y)\left[\alpha-\left(1-p^{i}-g\right)\right]
$$

Citizens choose whether to engage in clientelism or support the redistributive platform by comparing $V_{C}^{i}$ and $V_{R}^{i}$.

Citizens are able to determine the degree of inequality delegitimation beliefs to maximize their self-esteem. We assume that citizens can choose a set of behaviors and information processing choices conductive to a given inequality delegitimation belief $z^{i}$, and that their actual level delegitimation belief $\theta^{i}$ is a linear combination of this choice and a 'true' level of illegitimacy in the community, which we denote by $\tilde{\theta} .{ }^{6}$ In particular, we assume that delegitimation perceptions equal:

$$
\theta^{i}\left(z^{i} \mid \eta, \tilde{\theta}\right)=\eta \tilde{\theta}+(1-\eta) z^{i}
$$

The weight $\eta \in[0,1]$ captures the ability of people to influence their own values. $^{7}$

For simplicity, we assume that citizens choose $z^{i}$ so as to maximize, not overall utility, but the part of utility that concerns the psychological effect of inequality delegitimation. This formulation makes the model more tractable by separating the political decision and the inequality delegitimation decision. Citizens thus seek to maximize

$$
\theta^{i}\left(z^{i}\right)(\bar{y}-y)[\alpha-(1-p)]
$$

where this maximand depends on benchmark efficacy $p$ because this is the level of efficacy that applies when making the decision. Because this maximization problem has as possible solutions infinity and minus infinity, we impose a constraint that $\theta^{i}$ cannot be unboundedly high or low: $\theta^{i} \in[\underline{\theta}, \bar{\theta}]$. Under these assumptions, the choice of $\theta^{i}$ will be the same for all citizens and so we omit the superscript $i$ from now on.

The level of transfers offered as a clientelistic inducement $T$ is chosen by the rich patron. As the emphasis of this article is on the demand side of clientelism, we model the supply side in a minimal way to keep the model tractable. We assume that the patron wants to secure as many clients as possible, thereby reducing the chances of redistribution $P(T \mid$.), while spending as little as possible in transfers. We assume that transfers cannot be negative. Thus, the patron chooses transfers $T$ to maximize

$$
V_{P}(T)=1-P(T \mid .)-T
$$

Equilibrium. To close the model, we impose a rational expectations equilibrium condition. In particular, benchmark efficacy $p$ is citizen's (initial) belief regarding $P$, of 
how likely the redistributive platform is to succeed. We impose the condition that, in equilibrium, such belief $p$ needs to be equal to the true probability $P$. One can think of this condition as requiring us to focus on situations where citizens do not make strong or systematic mistakes.

Formally, the equilibrium of the model is a benchmark efficacy $p^{*}$, actual probability of redistribution $P^{*}$, level of clientelism $C^{*}$, delegitimation beliefs $\theta^{*}$, and patron transfers $T^{*}$ such that:

(1) citizen $i$ supports the redistributive platform if her utility from doing so is higher than the utility from engaging in clientelism (and vice versa),

$$
V_{R}^{i}\left(p^{i}\left(p^{*}\right), \theta^{*}, T^{*}\right) \geqslant V_{C}^{i}\left(p^{i}\left(p^{*}\right), \theta^{*}, T^{*}\right)
$$

(2) the true probability of redistribution $P$ equals the share of citizens $i$ choosing redistribution

$$
P^{*}\left(p^{*}, \theta^{*}, T^{*}\right)=\int_{i \text { s.t. } V_{R}^{i}\left(p^{i}\left(p^{*}\right), \theta^{*}, T^{*}\right) \geqslant V_{C}^{i}\left(p^{i}\left(p^{*}\right), \theta^{*}, T^{*}\right)} d i
$$

and the level of clientelism is the complementary share $C^{*}\left(p^{*}, \theta^{*}, T^{*}\right)=1-P^{*}$ $\left(p^{*}, \theta^{*}, T^{*}\right)$;

(3) the patron chooses transfers $T^{*}$ so that

$$
T^{*}=\underset{T \geqslant 0}{\operatorname{argmax}} 1-P^{*}\left(p^{*}, \theta^{*}, T\right)-T
$$

(4) choice $z^{*}$ and the corresponding inequality delegitimation $\theta^{*}$ satisfy

$$
\begin{aligned}
& z^{*}\left(p^{*}\right)=\operatorname{argmax} \quad \theta(z)(\bar{y}-y)\left[\alpha-\left(1-p^{*}\right)\right] \\
& \text { s.t. } \theta(z)=\eta \tilde{\theta}+(1-\eta) z) \text { and } \theta \in[\underline{\theta}, \bar{\theta}]
\end{aligned}
$$

thus

$$
\theta^{*}\left(p^{*}\right)=\eta \tilde{\theta}+(1-\eta) z^{*}\left(p^{*}\right)
$$

(5) citizens have rational expectations in the sense that

$$
p^{*}=P^{*}\left(p^{*}, \theta^{*}, T^{*}\right)
$$

\subsection{Results static model}

The model delivers multiple equilibria as shown in the following proposition. ${ }^{8}$

Proposition 1 (Static equilibrium). Define $B(\theta) \equiv g(\bar{y}-y)(1+\theta)$. If $\alpha>\frac{1}{2}, B(\underline{\theta})$ $<\frac{1}{4}<B(\bar{\theta})<1$, and focusing on the case $\sigma=\frac{1}{2}$, we have the following.

(1) There are three possible equilibria:

- $\quad$ traditional clientelism, $P^{*}=p^{*}=0, C^{*}=1, \theta^{*}=\underline{\theta}$; 
- $\quad$ modern clientelism, $P^{*}=p^{*}=1-\alpha, C=\alpha, \theta^{*}=\frac{1}{4 g(\bar{y}-y)}-1$;

- $\quad$ no clientelism, $P^{*}=p^{*}=1, C=0, \theta^{*}=\bar{\theta}$.

(2) Using the subscript $M$ for the modern clientelism equilibrium and $T$ for the traditional clientelism equilibrium, transfers $T_{M}^{*}>T_{T}^{*}$. The difference between the two can be decomposed into two positive parts:

$$
T_{M}^{*}-T_{T}^{*}=\sqrt{B\left(\theta_{M}^{*}\right)}-\sqrt{B\left(\theta_{T}^{*}\right)}+\sqrt{B\left(\theta_{T}^{*}\right)}-2 B\left(\theta_{T}^{*}\right)
$$

The model delivers three possible equilibria. Two of them are extreme, one with full clientelism, minimum efficacy, and the least possible inequality delegitimation $\underline{\theta}$; and another with no clientelism at all, maximum efficacy, and strong inequality delegitimation. We denote the full clientelism equilibrium as 'traditional clientelism' because it implies that social inequalities are legitimized.

In addition to these extreme equilibria, there is also an intermediate one. In this equilibrium, levels of efficacy, clientelism, and inequality legitimation are intermediate. We denote this equilibrium 'modern clientelism' because it does not involve the legitimation of inequality.

The multiplicity of equilibria result from two types of complementarities in the model. In order to understand how these complementarities come about, we explain the result in three steps. First, we consider how the actual probability of redistribution $P$ depends on benchmark efficacy $p$ and inequality delegitimation $\theta$, incorporating the clientelism choice of the citizens and the transfer choice of the patron. We write this as $P(p, \theta \mid$.$) indicating that the probability of redistribution P$ is considered for all possible levels of $p$ and $\theta$, not specifically the equilibrium levels. Then, as second and third steps, we incorporate the rational expectations equilibrium condition and the choice of inequality delegitimation which, together, pin down the equilibrium.

Figure 1 shows how the probability of redistribution $P(p, \theta \mid$.$) depends on bench-$ mark efficacy $p$ and inequality delegitimation $\theta$. Darker shades of gray indicate a higher actual probability of redistribution.

The probability of redistribution $P(p, \theta \mid$.$) is increasing in both benchmark effi-$ cacy $p$ and delegitimation $\theta$. This comes from the clientelism choices of citizens (the comparison of $V_{R}^{i}$ and $V_{C}^{i}$ ). Citizens are heterogenous in efficacy beliefs and this heterogeneity implies that some citizens may engage in clientelism whereas others choose redistribution. The probability of redistribution $P$ equals the share of citizens that choose redistribution. Intuitively, if generally people think that the redistribution platform has high chances of success (high benchmark efficacy $p$ ) or if they think that inequality is very illegitimate (high $\theta$ ), a greater share of them will support redistribution.

The clientelism choices of citizens also depend on the level of transfers $T$ that the patron chooses. However, as Figure 1 and the proof of Proposition 1 show, this pattern holds even when we account for the fact that the level of transfers $T$ is endogenous. The more efficacious citizens feel and the more they delegitimize inequality, the harder it is for the patron to buy them off. Thus, if efficacy $p$ and delegitimation $\theta$ are very low, it is very cheap for the patron to buy off everyone 


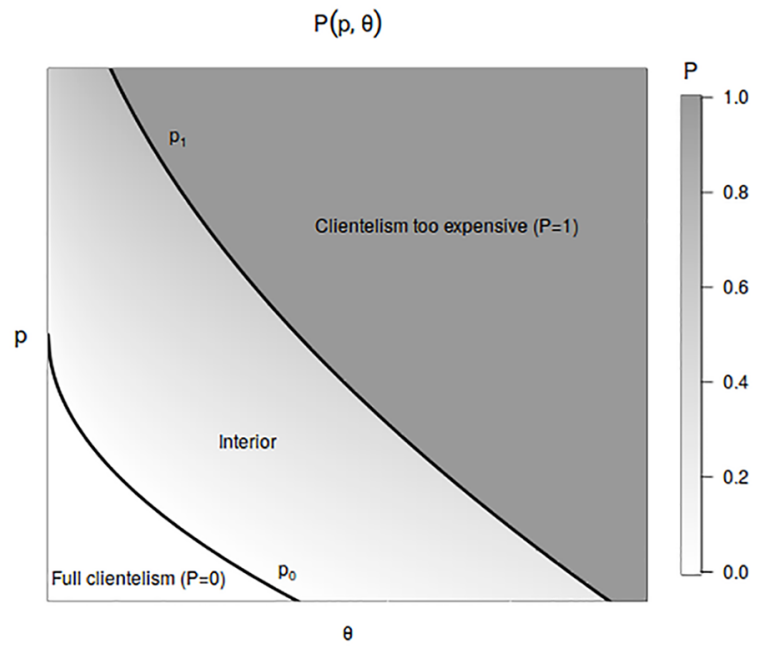

Figure I. Probability of redistribution $P(p, \theta)$.

and we are in the 'full clientelism' $(P=0)$ regime in Figure 1. As efficacy and delegitimation increase, the patron starts to give up clients gradually. This corresponds to the 'interior' regime, where some citizens are clients and others are not. As efficacy and delegitimation keep on increasing, eventually all citizens become too expensive and clientelism stops making sense for the patron. This is the "clientelism too expensive' $(P=1)$ regime, where no one becomes a client and redistribution is all but certain.

Figure 1 shows the probability of redistribution $P(p, \theta \mid$.) for all possible values of benchmark efficacy $p$ and delegitimation $\theta$. However, in the model, both $p$ and $\theta$ are endogenous. How are they determined? We consider as a second step benchmark efficacy $p$, while still taking delegitimation $\theta$ as given.

Benchmark efficacy $p$ is pinned down in the model via the rational expectation condition: of all the possible levels of benchmark efficacy $p$, the rational expectation condition singles out those that are consistent with the actual probability of redistribution $P$, where $p=P(p)$. This is depicted in Figure 2: different levels of benchmark efficacy can be sustained in the rational expectation equilibrium depending on the level of inequality delegitimation $\theta$. We thus write the rational expectation levels of benchmark efficacy as $p(\theta)$. This figure builds on the previous one: it shows the $(p, \theta)$ space with the boundaries of the 'full clientelism,' the 'interior,' and the 'clientelism too expensive' regimes that implied different probability of redistribution $P(p, \theta)$. On top of this is, the figure adds in bold the levels of benchmark efficacy $p(\theta)$ consistent with rational expectations.

The figure shows that it is possible to 'rationally' sustain high, medium, and low benchmark efficacy beliefs in this model. In other words, a priori, $p(\theta)=0$ can potentially be an equilibrium, and so $\operatorname{can} p(\theta)=1$, as well as other intermediate 


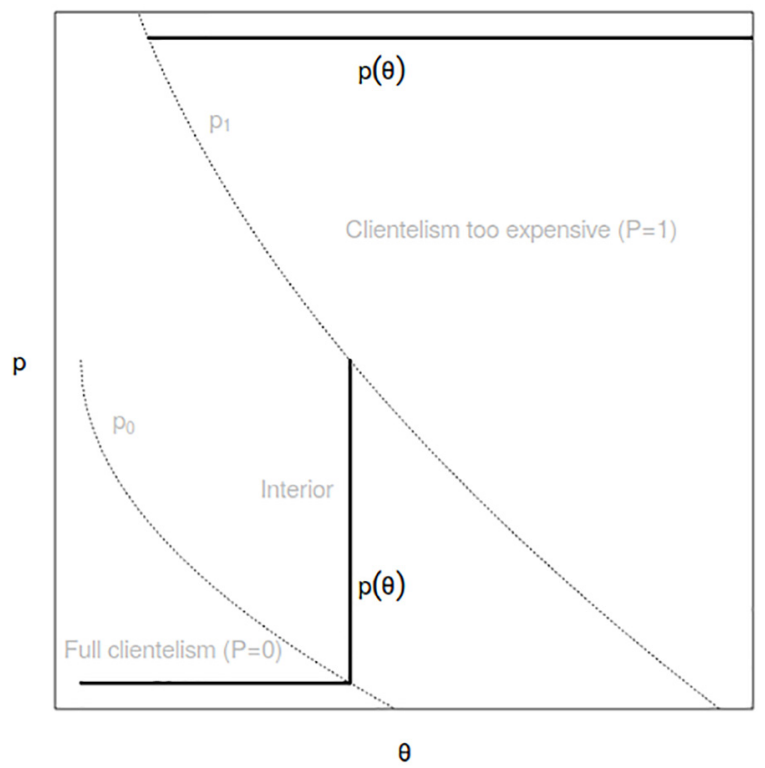

Figure 2. Benchmark efficacy levels consistent with rational expectations.

values. This multiplicity comes from the first complementary in the model, between efficacy and redistribution, which makes it possible to sustain many different levels of efficacy. High efficacy perceptions induce citizens to support redistribution; this leads to little clientelism and a high probability of redistribution which validates the initial efficacy perceptions. This corresponds to the top section of $p(\theta)$ in Figure 2, where the community is in the 'clientelism too expensive' regime, and no one becomes a client $(P=1)$. The converse leads to the bottom section of $p(\theta)$ in the figure, where the community is in the 'full clientelism' regime. Intermediate levels of efficacy beliefs can also be supported in equilibrium, corresponding to the vertical section of $p(\theta)$ in the interior regime. Efficacy perceptions in this model are 'self-fulfilling prophecies.'

However, as the figure shows and the notation $p(\theta)$ reminds us, the levels of efficacy and clientelism that can be sustained in this model depend on inequality delegitimation. For instance, only communities that delegitimize inequality strongly will be able to support non-clientelistic equilibria.

The third and final step of the model solution integrates the endogeneity of delegitimation beliefs $\theta$. Citizens choose how much to delegitimize inequality in order to maximize their self-esteem. Whether or not it pays off to delegitimize inequality depends on efficacy beliefs $p$. Therefore, this choice delivers a function $\theta(p)$. We can depict this function adding it to the previous figure, as shown by the bold dashed line in Figure 3.

The schedule $\theta(p)$ is increasing in $p$ : if citizens have strong efficacy perceptions and believe that redistribution is likely ( $p$ high), it pays off to consider inequality as 


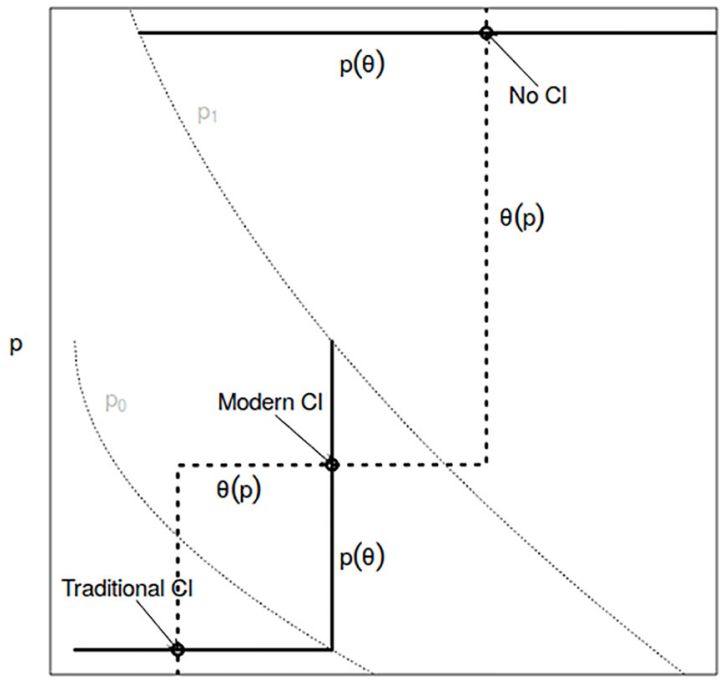

$\theta$

Figure 3. Static equilibria.

illegitimate; but if citizens feel inefficacious rather powerless ( $p$ low), thinking that redistribution has no chance, they are better off legitimizing inequality. This result is consistent with recent empirical findings in social psychology of legitimacy. Experimental evidence has shown that powerlessness (Van der Toorn et al., 2015), or perceptions that the environment is hard to change (Johnson and Fujita, 2012; Pellicer et al., 2018, 2019) lead people to find the system more legitimate and/ or display preferences against changing it.

The equilibria of the model are the intersections between the schedules $p(\theta)$ and $\theta(p)$. There are three intersections that correspond to the three equilibria in Proposition 1. The multiplicity of equilibria here emerge from a second complementarity in the model, between inequality delegitimation and efficacy/redistribution. When citizens feel powerless and inefficacious, they believe that redistribution will not occur and inequality will remain high. In that situation, they are better-off by legitimizing inequality. Considering inequality legitimate, in turn, makes redistribution less appealing, further consolidating clientelism and inefficacy beliefs. This is the traditional clientelism equilibrium. The reverse situation is also possible, with high efficacy beliefs, redistribution demands, and inequality delegitimation reinforcing each other. This is the no clientelism equilibrium. The modern clientelism equilibrium has intermediate values in these variables.

The second part of Proposition 1 shows that clients get a better deal from clientelism in the modern clientelism equilibrium relative to the traditional one. The decomposition shown in the proposition shows that there are two reasons for this. 
First, the delegitimation of inequality in the traditional clientelism equilibrium $\theta_{T}^{*}$ is lower than in the modern clientelism equilibrium $\theta_{M}^{*}$. This implies that citizens in the traditional equilibrium are willing to give up redistribution more easily and are cheaper to buy than in the modern clientelism equilibrium.

Second, even for given inequality delegitimation, there is a positive difference between the transfers in the two equilibria. This difference comes the fact that the traditional clientelism equilibrium features 'full clientelism' (the transfers chosen by the patron are a corner solution); whereas the modern clientelism equilibrium features citizens at the margin between clientelism and redistribution (transfer choice is an interior solution). The patron gives more transfers when transfers are useful, and transfers are more useful when they manage to sway many voters. When there are few or no 'marginal' voters (as in the traditional clientelism equilibrium), the patron can afford to lower transfers without losing much.

\section{Dynamic extension}

The static equilibrium tells us that communities may end up being highly redistributive, or clientelistic in the traditional or in the modern sense. We consider here a dynamic extension of the model that provides insights on the conditions under which communities will converge to each of these equilibria.

In keeping with the paper's focus on the client, and in particular on client's perceptions, we keep the patron side as simple as possible, and focus on the dynamics of clientelism, efficacy, and inequality delegitimation beliefs.

\section{I. Set-up}

In the dynamic extension, each citizen has one offspring, and dynasties are indexed by $t$.

There are two main additions to the static model. First, the choice of inequality delegitimation is made (arguably) more realistic. In the static model, individuals themselves selected their own delegitimation beliefs. Now we assume that the level of delegitimation belief of generation $t+1$ is (partly) determined by the educational choices $z_{t}$ of their parents: $\theta_{t+1}\left(z_{t}\right)$.

Second, in order to keep the model tractable, we assume that income is generated from capital $k$ (that can be thought of as land), which transforms into income following a simple linear technology: citizen income is $y=k$ and average income is $\bar{y}=\bar{k}$. At the end of their life, citizens consume the totality of their income and pass over to their offspring all their capital $k$. This allows us to keep income constant across generations regardless of income changes within a generation: even if the redistributive platform succeeds and redistribution takes place, citizens in the next generation start with capital $k$ and thus face the same problem all over again.

The timing is as follows. Citizens, again indexed by $i$, in generation $t$ are born with capital $k$ (constant across generations), and benchmark efficacy $p_{t}$, and acquire their inequality delegitimation level $\theta_{t} \cdot{ }^{9}$ They produce $y$ of income (also constant across generations) and have an offspring. Then they choose the level of 
delegitimation $z_{t}$ to transmit to their offspring. ${ }^{10}$ At the same time, the patron chooses the level of transfers $T_{t}$. Then the idiosyncratic efficacy shock $\epsilon^{i}$ takes place. Citizens then decide whether to engage in clientelism or support the redistributive platform. This determines the actual probability of redistribution $P_{t}$ and the level of clientelism $C_{t}$ in the community. The corresponding redistribution and/or transfers take place and citizens consume all their income and die, leaving their capital $k$ to their offspring.

Most of the elements of the model remain as in the static model. The utility function of citizens when choosing clientelism or support for redistribution $V_{C}$ and $V_{R}$ are given by (1) and (2), with the appropriate time subscripts (i.e., $y, \bar{y}, g$, and $\alpha$ are constant, whereas $p_{t}^{i}, \theta_{t}$, and $T_{t}$ are time varying). The idiosyncratic efficacy shock $\epsilon^{i}$ follows a uniform distribution with mean zero and extremes $\pm \sigma$. The patron chooses transfers $T_{t}$ in order to maximize $1-P_{t}\left(T_{t}\right)-T_{t}$, also as in the static model. This implies that even if the model is dynamic, decisions of actors are myopic. This is an important limitation of the model which we impose for tractability. Even with these limitations, we believe that the dynamic extension provides useful insights on the conditions under which communities will converge towards different types of clientelism equilibria.

As before, actual delegitimation perceptions are a combination of (parental) choices and the 'true' (il)legitimacy of inequality in the community $\tilde{\theta}$ :

$$
\theta_{t+1}\left(z_{t}\right)=\eta \tilde{\theta}+(1-\eta) z_{t}
$$

The weight $\eta \in[0,1]$ captures now the ability of parents to influence children's values. A high $\eta$ implies that parents have little influence.

In addition, as before, we assume that parents transmit legitimation values in order to maximize self-esteem, in this case their children's. However, it is reasonable to assume that there are adjustment costs in the transmission of values, in the sense that it is psychologically costly for parents to transmit values far away from those they believe themselves. For simplicity, these costs are assumed to be quadratic. The maximization problem of the parent is therefore

$$
\operatorname{Max} \theta_{t+1}\left(z_{t}\right)(\bar{y}-y)\left(\alpha-\left(1-p_{t}\right)-\frac{1}{2}\left(z_{t}-\theta_{t}\right)^{2}\right.
$$

Because, in this case, the solutions to the maximization problem are bounded, it is not necessary to impose the additional condition that $\theta^{i} \in[\underline{\theta}, \bar{\theta}]$.

In the static model, we imposed rational expectations in the formation of benchmark efficacy beliefs $p_{t}$. Here we impose a possibly more realistic assumption that children's benchmark efficacy beliefs are based on the clientelism/redistribution choices of their parents. In other words, we assume a sort of 'adaptive' expectations whereby the benchmark efficacy of generation $t+1, p_{t+1}$ equals the actual probability of redistribution in period $t: p_{t+1}=P_{t}$.

For completeness, we assume there are exogenously given initial levels of capital, benchmark efficacy, and inequality delegitimation at the start of life of generation $0: k_{0}$, $p_{0}$, and $\theta_{0}$. 


\subsection{Dynamics and stable steady states}

The dynamic model yields the following key result.

Proposition 2 (Stable steady states). There are two dynamic regimes, depending on whether diversity of opinion $\sigma$ and parental influence on children's values $\eta$ are high or low.

- If, for given $\eta, \sigma$ is sufficiently low or if, for given $\sigma, \eta$ is sufficiently low:

- there are two stable steady states, the traditional clientelism steady state and the no clientelism steady state;

- if initial levels of efficacy and/or inequality legitimation are low, communities will converge to the traditional clientelism steady state; otherwise, they will converge to the no clientelism steady state.

- If, for given $\eta, \sigma$ is sufficiently high or if, for given $\sigma, \eta$ is sufficiently high:

- there are two stable steady states, the modern clientelism steady state and the no clientelism steady state;

- communities will converge towards the modern clientelism steady state unless initial efficacy and inequality delegitimation are sufficiently high to make clientelism not worth it for the patron.

Proposition 2 states that the path that a community follows depends on the extent of diversity of opinion in the community, on how much influence parents have on children's values, and on its starting levels of efficacy and delegitimation. Figure 4 illustrates the main results, depicting the dynamics of the system for the two regimes in the proposition.

To understand Figure 4, it is useful to recall the solution of the static model. The graphs in Figure 4 are very similar to the graph for the static equilibrium in Figure 3. Both have as axis efficacy $p$ and delegitimation $\theta$. There is a bold solid line representing how efficacy depends on delegitimation (labeled here $\Delta p=0$ ) and

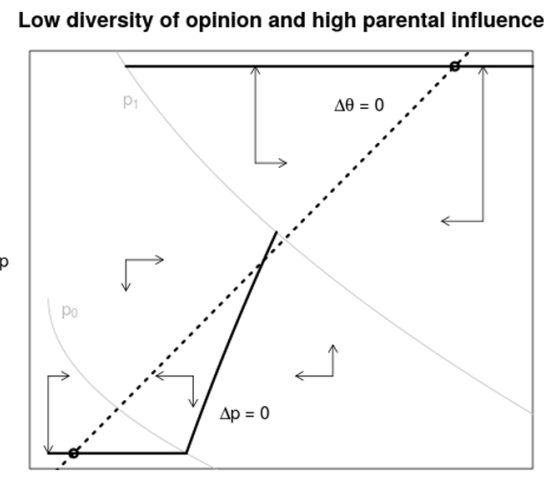

$\theta$
High diversity of opinion and low parental influence

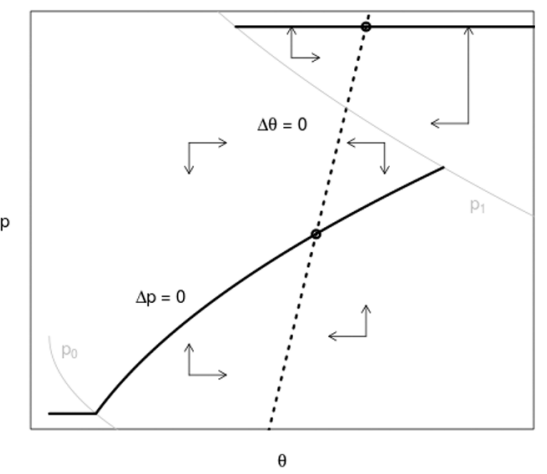

Figure 4. Dynamics. 
a bold dashed line representing how delegitimation in turns depends on efficacy (labeled here $\Delta \theta=0$ ). These lines now capture situations where efficacy and delegitimation, respectively, are at rest. The intersection between the two lines shows the steady states of the dynamic model, i.e., the situations where efficacy and delegitimation are simultaneously at rest. These points are the counterpart of the multiple equilibria in the static model and can be considered 'dynamic equilibria.' The key is that some of these equilibria will be stable and some others will not, and communities are likely to end up only in the stable ones.

There are two important differences between the static and dynamic figures. First, we now have information on how the system moves outside these resting positions. This is given by arrows in the figure. This gives us which equilibria are stable and which are unstable. Second, in contrast to the static model, the slopes of the equilibrium curves are neither horizontal nor vertical. They now depend on the parameters, and in particular the parental influence parameter $\eta$ and the diversity of opinion $\sigma$, which is now not constrained to $\frac{1}{2}$. In particular, the left graph shows a case where $\eta$ and $\sigma$ are low. As the appendix shows, this implies that the line $\Delta \theta=0$ is flatter than the middle section of $\Delta p=0$. The right graph shows the opposite case. The dynamics of the system (i.e., the direction of the arrows) turn out to be different in these two cases.

Proposition 2 states that traditional clientelism will be stable if there is little diversity of opinion in the community and if parents have a major influence on their children's values (low $\sigma$ and $\eta$ ). This is shown in the left panel of Figure 4 with arrows that tend towards the equilibrium at the bottom left corner. When there is a lot of diversity of opinion in the community and parents have little influence on children, the modern clientelism equilibrium is stable. This is shown in the right panel, with arrows pointing towards the equilibrium at the center.

The intuition behind this result is that high diversity of opinion and low paternal influence tend to break the complementarities that support traditional clientelism. When there is little diversity of opinion, the dynamic path of efficacy is explosive: efficacy tends to go towards extremes where either everyone becomes a client or no one does. Then, the complementarity between inefficacy and clientelism in the static model prevails. If efficacy is low, essentially everyone will find it worthwhile to engage in clientelism; the next generation will have as benchmark a perception of almost zero efficacy, and the society will remain clientelistic. Diversity of opinion, however, can break this cycle. If idiosyncratic shocks are sufficiently large, even in a situation where most parents are clientelistic, there will be a substantial amount of children that are exposed to experiences that lead to entertain relatively high efficacy, and the society will avoid becoming totally clientelistic. Efficacy will then tend to converge towards intermediate values.

Regarding, inequality delegitimation, there are two forces that govern its dynamics. First, there is a tendency to go towards the 'true' level $\tilde{\theta}$. This is because the actual delegitimation beliefs in a generation is partly determined by its 'true' level in the community and people find it difficult to pass on to their children values very different from their own. However, legitimation perceptions also move independently of real injustice, from the attempts of parents to protect their 
children's self-esteem, as in the static model: If efficacy is low enough, parents will realize that high inequality is largely inevitable and will want to shield their children from the pain of bearing a harmful sense of injustice throughout their lives. Thus, they will make them less sensitive to injustice and delegitimation perceptions will decrease over time. The reverse occurs if efficacy is high.

The relative importance of 'reality' considerations versus parental influences is determined by $\eta$, the scope of parents to affect children's perceptions. If $\eta$ is low and children's values are heavily influenced by their parents, inequality delegitimation perceptions will drift independently of reality following parental attempts to protect their children. In contrast, if parents have little influence on children's values (high $\eta$ ), regardless of the previous generation efforts, the following generations will display delegitimation perceptions approaching ever closer the 'real' $\tilde{\theta}$.

A good way to summarize this discussion is to interpret Proposition 2 in terms of the degree of informational connectivity of the community towards the outside world. The complementarities that drive traditional clientelism in the dynamic model rest on the intergenerational linkages of efficacy and legitimation. It is the parental clientelism choices and their attempts at protecting children self-esteem that set the community in a path towards traditional clientelism. These intergenerational linkages are most prominent in informationally isolated communities. In communities that are strongly connected to the outside world, alternative external political narratives have a stronger contribution on children perceptions. This breaks the complementarities between inefficacy, clientelism, and legitimation, and allows the community to settle in an intermediate equilibrium. Proposition 2 can be interpreted as saying essentially that traditional types of clientelism are more likely to occur in informationally isolated communities. As communities become more informationally connected, clientelism may transform into a more instrumental, 'modern' type.

Whereas the type of clientelism equilibrium that is stable depends on parameters, the 'no clientelism' equilibrium at the top right of the graphs is always stable, regardless of diversity of opinion or the extent of parental influence. Communities end up in the no clientelism equilibrium if citizens start (or exogenously become) sufficiently efficacious and delegitimizing. Then, the community gets into a definitive path away from clientelism with no turning back: citizens become too expensive and the patron gives up clientelism.

\section{Discussion}

The model delivers insights on different types of clientelism, and on how traditional clientelism may transform into a modern variety. This section discusses these mechanisms and illustrates them with examples from the literature. 


\section{I. Traditional and modern clientelism}

An important insight from the model concerns different types of clientelism. The model predicts two types of clientelistic equilibria, 'traditional' and 'modern,' that differ in inequality legitimation, stability, and in the benefits that the clients obtain.

The distinction between traditional types and modern types of clientelism is clearly made by scholars of clientelism in the 1960s and 1970s (e.g., Weingrod, 1968). Traditional clientelism is embedded in social relations, involves an exchange of loyalty in a setting viewed as largely legitimate by the clients, and is considered to be more durable and stable. Modern clientelism, such as machine clientelism or vote-buying, is generally viewed as a one-shot and largely anonymous quid pro quo exchange of money or small goods for votes.

The term traditional might lead to the misperception that this form of clientelism is waning or outdated. Traditional ties often underlie clientelistic exchanges. Even in settings that appear 'modern,' the type of clientelism experienced from the client's point of view, is often closer to the traditional type. Discussing the operation of party machines in African countries in the 1960s, Lemarchand (1972) described the 'neo-traditional machine,' in which 'traditional micro-level solidarities provide the essential linkages between the party and the masses.' In this case, he argues, 'the machine is superimposed upon, and in some ways tributary to, the clientelistic subsystem' (p. 114). Similarly, Archer's (1990) analysis of broker clientelism in Colombia shows that a 'primary' patron-client cluster 'strongly dependant on kinship and localist ties is the basic building block' of these modern networks (pp. 22 23). Such primary relationships involve high levels of affect and respect (p. 31) as in the traditional form of clientelism. More recently, Gottlieb (2017) and Kramon (2017) also noted the importance of traditional leaders as brokers in clientelistic exchanges in some African countries.

Legitimation. One of the main differences between the two types of clientelistic equilibria in the model is the degree of inequality legitimation by citizens. In particular, citizens are predicted to legitimize social inequalities in the 'traditional' steady state. It is this distinction that largely warrants the use of the terms traditional versus modern.

Legitimacy is one of the key notions in the characterization of traditional forms of clientelism. Traditional clientelism involves 'loyalty' and 'deference' from the client's side and affection as a key feature of the links between client and patron (Landé, 1977: p. XXIX). These ties are often likened to father-children relations, where the patron affords protection and security and the client reciprocates with deference and respect. Accordingly, Silverman's (1977) work on clientelism in Central Italy notes the "close connection between "patronage" and "paternalism", (p. 297).

More recent ethnographic work suggests a similar role of paternalism and deference in traditional clientelistic ties. Arghiros (2001) described patrons in traditional forms of clientelism in Thailand as 'archetypal paternalistic and authoritarian leader,' 'respected by villagers of all ages' (pp. 74-75). Paller's (2014) work on political patrons ('big men') in urban Ghana argued that 'leaders are expected to be the patriarchs not only of their biological families, but also of a broader 
constituency' and become 'the head of a group of followers who perceive their leader as a father figure' (p. 127).

A somewhat different way of legitimizing unequal relations is the traditionalstyle broker client relations described by Auyero (1999, 2000) in present-day Argentina. Instead of perceiving patrons as father figures, they are described as 'friends.' Clients depict brokers as 'being so good' or 'always lending a hand.' Although brokers control material resources on which clients rely, clients deemphasize and rationalize the inequality in their relationship. Similarly to more standard traditional relations, the unequal status-quo in which the relation takes place is not put into question by the clients.

In contrast, modern clientelism is typically characterized as an exclusively material transaction involving purely opportunistic patrons and clients. Rather than legitimizing the relationship or inequality in general, clients are portrayed as having a highly cynical attitude towards politicians (Becerra Mizuno, 2013; Gay, 1998; Lazar, 2004). This attitude is exemplified by a vote-seller in the Dominican Republic: '(the parties) are all the same. They come around during elections, and never again. If I can get a few pesos for voting, then that's enough for me' (Gonzalez-Acosta, 2008).

Stability. The dynamics of the model suggest that modern clientelism will be relatively fluid, whereas traditional clientelism will be very stable. In the modern case, any change in parameters will affect the schedules $\Delta \theta=0$ and $\Delta p=0$, leading to a change in the steady state, and thus to a permanent change in the level of clientelism. The situation is different in traditional steady states. There, changes in the environment that affect the benefits and costs of clientelism will have no fundamental or long-lasting effect on clientelism. Even if these changes succeed in affecting clientelism in the short run the values of clients make the community return endogenously to the traditional situation. The very fact that social inequality is legitimized in the traditional steady state makes this situation very difficult to change.

Indeed, in the literature, one of the key characteristics of traditional clientelism is its stability. Moreover, as in the model, authors link this stability directly to legitimacy (Archer, 1990; Powell, 1970; Silverman, 1977; Weingrod, 1968). An example of the role of legitimation practices for the resilience of clientelistic relations is given by the work of Foltz (1969) on Senegal. A 'patron does not buy client's support and recognition' (emphasis in the original). 'Public gift-giving is a patterned process, designed to ennoble the giver and reflect "high concern for honor", not an underhanded and reprehensible attempt to buy support and status.' Thus, the author concludes: 'As such, it is a particularly difficult pattern to extirpate, and one that is likely to continue to pervade many aspects of Senegalese life' (p. 244). Other authors note how the stability of traditional clientelism is cemented by creating vertical kinship between patron and client, for example by patrons becoming godfathers of clients' children (e.g., Archer, 1990; Silverman, 1977).

Authors have also noted how the legitimation patterns in traditional clientelism may delay horizontal mobilization, as in the model. As Silverman (1977: pp. 296\{297) observes, 'the paternalism of the mezzandria [the landlord-peasant 
relation giving rise to "traditional" clientelism], has often been pointed to as a factor in delaying the spread of labor agitation to the Central Italian hill region for several decades after its onset in many agricultural areas of the nation about 1870 .'

Client's benefits. The model suggests that clients will receive a better deal in modern settings relative to traditional ones. This point has been frequently made in the literature. The argument is usually made from the supply side. Modern clientelism has brought an increase in patron competition that decreases their relative bargaining power (Corstange, 2018; Hilgers, 2012: e.g.,).

Our model complements this insight by focusing on the demand side. In the model there are two reasons why traditional clients get a worse deal. First, traditional steady states are situations of full clientelism, where the patron has already secured the whole community and can thus afford to save on transfers. This is also about competition: it is the fact that the patron does not need to compete for clients in traditional settings that gives her extra bargaining power. Our model adds to the literature in showing that competition need not be about how many patrons there are, but more generally about the availability of other valued political alternatives for clients. Traditional settings reduce the bargaining power clients because the horizontal alternative is pushed out of the competition.

The second reason why, in the model, clients get a bad deal in traditional settings is that the very legitimation of inequality associated with traditional clientelism weakens their bargaining power. This can address the puzzle of how this type of clientelism can survive even in current settings, even if there are many socioeconomic and institutional breaks to clientelistic politics (see Nichter (2018) for a discussion of such factors). Clients can get stuck in a situation where their very own values weaken their bargaining power because these values are a psychological adaptive reaction to a situation where citizens feel inefficacious.

\subsection{Breaking versus transforming clientelism}

There are two paths by which traditional types of clientelism may disappear in the model. Traditional clientelism may either fully give way to horizontal, programmatic, mobilization or it might transform into a more modern type.

Current literature proposes several explanations for how clientelism gives way to programmatic politics. Studies focus on how increases in citizen income or institutional changes such as the introduction of the secret ballot increased the cost of clientelism for patrons (see Aidt and Jensen (2017), Kitschelt and Kselman (2013), and Stokes et al. (2013) as well as the discussion in Nichter (2018)). ${ }^{12}$

Our model emphasizes the role of clients beliefs for the disappearance of clientelism. In the model, dramatic shifts of parameters that massively strengthen clients can bring communities to a path that leads them away from clientelism. For instance, an exogenous increase in efficacy beliefs can turn the dynamics of efficacy and legitimacy perceptions upside down leading to ever more efficacy, less legitimation, and less clientelism. 
A good illustration of these dynamics is given by Thompson (1963), the classic account of the emergence of worker organization in 19th century England. Before the 19th century, the status quo was maintained by a mix of deference, clientelistic inducements, and force. This changed during the beginning of the 19th century, as horizontal organization consolidated: there was a 'general and radical change in the character of the labouring classes. The poor, when suffering and dissatisfied, no longer make a riot, but hold a meeting -instead of attacking their neighbors, they arraign a Ministry' (p. 464).

Thompson (1963) showed that the process of horizontal organization was accompanied by working class self-confidence (i.e., efficacy), and away from deference towards elites (i.e., delegitimation). Summarizing the main point of his book in a later postscript, he argued: 'I have tried [...] to show that they were coming to act, think, and feel, not in the old modes of deference and parochial seclusion, but in class ways' (p. 937). Thompson emphasized the critical role of efficacy perceptions: 'It was a question of morale [emphasis in original]; at its simplest level it meant that it was possible for individual working men to have a sense [...] of sustained commitment to a movement for their own class objectives, and a confidence that enabled them to stand up against the physical and moral resources of their opponents' (p. 938). These changes in horizontal organization, self-confidence, and delegitimation were mutually reinforcing: 'The effect upon the reformers' morale of each successive demonstration was instantaneous. With each breach in the walls of deference, the waters of insubordination swept through' (p. 748).

What kickstarted this process? This was a turbulent moment with many major simultaneous structural changes, but two major 'exogenous shocks' may have played a role. First, the French Revolution of 1789 represented a massive shock to efficacy perceptions. Second, the Industrial Revolution eroded deference: 'This growth in self-respect and political consciousness was one real gain of the Industrial Revolution. It dispelled some forms of superstition and deference, and made certain kinds of oppression no longer tolerable' (p. 464).

The other way in which traditional clientelism may disappear in the model is by becoming transformed into a more modern type. Scott (1972), describing the transformation in the nature of clientelistic linkages in South East Asia, argues that one of the key developments has been a loss of its 'traditional legitimacy.' This implied a shift in the balance between affective and instrumental ties in the direction of the latter, with exchanges becoming more 'monetized' and focusing 'more on the rate of return from the relation rather than on its durability' (pp. 106-107). Silverman (1977) gives another example of such transformation in her study of Central Italy during the second half of the 19th and first half of the 20th century. She argues that as traditional clientelism disappeared, the political linkages of citizens changed, including more 'structurally horizontal links' as well as clientelistic relations, but of a short and more targeted nature (p. 303).

In the model, such transformation can come about via an increase in informational connectivity of the community, which changes the dynamics of the system, breaking the complementarity between efficacy and delegitimation. Weingrod (1968) studied such transformation of clientelism in the Italian island of Sardinia. His work explicitly 
attributes the reason for such transformation to an increase in the community's connectivity to the outside world. Through the evolution of indicators of community isolation, such as intra-village marriage or intra-village godfathering, he shows how such evolution coincides with the transformation in clientelism. Noting the increasing connections with the outside in terms of education, economic ties, or the spread of mass media such as radio or television, he argues that this new participation in the 'mass society' breaks old linkages and gives predominance to new ones where political party patronage becomes key. More recent studies (see Archer (1990) for Colombia, Arghiros (2001) for Thailand, and Shefner (2001) for Mexico) note a similar role of connectivity for the transformation of clientelism away from paternalistic types and towards a more instrumental vote-buying type.

\section{Concluding remarks}

This article has argued that bringing insights from social psychology, notably on inequality legitimation, can fruitfully advance research on clientelism. In particular, this can provide a novel perspective on why some poor people engage in clientelism whereas others do not, and on why some communities experience traditional as opposed to vote-buying types of clientelism.

We have proposed a model where citizens decide whether to engage in clientelism or support a redistributive platform and hold beliefs on efficacy and the legitimation of inequality. Many insights of the model derive from the fundamental insight that people adapt their values and beliefs to features of their environment, as emphasized in recent research in social psychology (Duckitt and Sibley, 2010; Jost et al., 2003). In the model, the clientelism choices of the poor affect their efficacy and inequality legitimation beliefs, and vice versa. This interaction between political choices and beliefs generates multiple equilibria with different levels and different types of clientelism.

We believe that bringing the client and her beliefs and values into the center stage of studies of clientelism can broaden our understanding of the mechanics, dynamics, and welfare implications of clientelism.

\section{Acknowledgements}

We would like to thank Harold Kincaid, Juanita Vasquez, Viola Lucas, Marina Dodlova, Bo Rothstein, Jeff Staton, Marcia Grimes, Victor Lapuente, and participants at the 2016 QoG Internal Conference in Nice, and the 2016 EPSA, EPCS, and APSA conferences for very helpful comments. All remaining errors are ours.

\section{Declaration of Conflicting Interests}

The author(s) declared no potential conflicts of interest with respect to the research, authorship, and/or publication of this article.

\section{Funding}

The author(s) received no financial support for the research, authorship, and/or publication of this article. 


\section{ORCID iD}

Eva Wegner (iD https://orcid.org/0000-0002-2014-0460

\section{Appendix}

Proof. 1. We proceed as follows. First, we derive the clientelistic decisions of citizens given all the others variables and parameters of the model. Second we compute the probability of redistribution $P(p, \theta, T \mid$.$) , again given all variables and$ parameters of the model. Third, we solve for the patron choice of transfers $T(p, \theta \mid$.$) , given benchmark efficacy and inequality delegitimation. Then we solve$ for the inequality delegitimation choice to obtain $\theta(p)$, given benchmark efficacy. Finally, we impose the rational expectations condition that $p=P(p)$.

Comparing $V_{C}$ and $V_{R}$ in (1) and (2), and solving for $p^{i}$ gives a critical value of efficacy $\hat{p}$ above which people support redistribution: choose redistributive platform if $p^{i}>\hat{p}(\theta, T) \equiv 1-\frac{B(\theta)}{T}$, where $B(\theta) \equiv g(\bar{y}-y)(1+\theta)$.

The probability of redistribution $P(p, \theta, T \mid$.$) , given the values of p, \theta$, and $T$, equals the share of citizens with efficacy $p^{i}>\hat{p}$. As $p^{i}=p+\epsilon^{i}$, this share is $\operatorname{Prob}\left(\epsilon_{i}>\hat{p}-p\right)$. Using the fact that $\epsilon_{i}$ is distributed following a uniform distribution with mean zero and extremes $\pm \sigma$ yields

$$
P(p, \theta, T \mid y, \bar{y}, \sigma, g)= \begin{cases}0 & \text { if } p \leq \hat{p}(\theta, T)-\sigma \\ \frac{1}{2 \sigma}(p+\sigma-\hat{p}(\theta, T)) & \text { if } \hat{p}(\theta, T)-\sigma<p \leq \hat{p}(\theta, T)+\sigma \\ 1 & \text { if } p>\hat{p}(\theta, T)+\sigma\end{cases}
$$

where $\hat{p} \equiv 1-\frac{B(\theta)}{T}$

The patron chooses transfers in order to maximize his utility $V_{P}=1-P(p, \theta, T)-T$, subject to $T \geqslant 0$, where $P(p, \theta, T)$ is given just above. There are three regimes of transfers chosen by the patron:

$$
T(p, \theta \mid y, \bar{y}, \sigma, g)=\left\{\begin{array}{cl}
\frac{B(\theta)}{1-p-\sigma} & \text { if } p \leq p_{0}(\theta) \quad(\text { Full clientelism : } C=1) \\
\sqrt{\frac{B(\theta)}{2 \sigma}} & \text { if } p_{0}(\theta)<p \leq p_{1}(\theta)(\text { Interior : } 0<C<1) \\
0 & \text { if } \left.p>p_{1}(\theta) \quad \text { (Clientelism too expensive : } C=0\right)
\end{array}\right.
$$

where $p_{0}(\theta) \equiv 1-\sigma-\sqrt{B(\theta) 2 \sigma}$ and $p_{1}(\theta) \equiv 1+\sigma-2 \sqrt{B(\theta) 2 \sigma}$.

The interior solution $\sqrt{\frac{B(\theta)}{2 \sigma}}$ follows from the first-order condition of the maximization problem of the patron:

$$
\frac{B(\theta)}{2 \sigma T^{2}}-1=0
$$

which also implies clearly that the second-order condition holds.

There are three potential corner solutions. First, from the constraint $T \geqslant 0$. At the corner $T(p, \theta)=0, \hat{p} \rightarrow-\infty$ and, therefore, $P=1$ and $V_{P}=0$. 
The other two potential corner solutions correspond to the range of values where $P=0$ and $P=1$ in Equation (3). For these, $V_{P}$ equals $1-T$ and $-T$, respectively. The latter can never be optimal because it will always be lower than the corner solution $T(p, \theta)=0$. The former is maximized with the minimum possible transfers consistent with the domain over which it applies. This domain is $p \leq \hat{p}-\sigma$, and the minimum $T(p, \theta)$ in this domain is $\frac{B}{1-p-\sigma}$, the transfer applying in the 'full clientelism' case.

The corner solution $T(p, \theta)=0$ applies when the utility $V_{P}$ evaluated at the interior solution is lower than zero. This happens if $p>1+\sigma-2 \sqrt{B(\theta) 2 \sigma} \equiv p_{1}(\theta)$. This is the boundary for the 'clientelism too expensive' regime.

It can be readily checked that $V_{P}$ evaluated at the interior solution is higher than or equal to that evaluated at the full clientelism solution. Thus, the interior solution holds as long as the relevant corner constraint $p \leq \hat{p}-\sigma$ evaluated at the interior solution is fulfilled. This holds when $p>1-\sigma-\sqrt{B(\theta) 2 \sigma} \equiv p_{0}(\theta)$, which is then the boundary for the 'full clientelism' regime.

The thresholds $p_{0}$ and $p_{1}$ concern comparisons between the interior regime and the other two regimes. They are relevant as long as the interior regime applies. Otherwise, the relevant threshold is from the comparison between the full clientelism and the 'clientelism too expensive' regimes, which deliver a threshold $p_{2}=1-\sigma-B$. This threshold is relevant when $B>2 \sigma$. Then, $p_{1}$ and $p_{0}$ are not relevant because $p_{0}>p_{1}$ and $p_{2}>p_{0}$, which imply that the relevant comparison is between the 'full clientelism' and the 'clientelism too expensive' regimes, which is given by $p_{2}$. Thus, the result in the proposition holds as long as $B(\theta)<2 \sigma$. In equilibrium, this condition is ensured by the simplifying assumptions of the proposition: $\sigma=\frac{1}{2}$ and $B(\bar{\theta})<1$.

By plugging-in the expression for transfers $T(p, \theta)$ into the actual probability of redistribution $P(p, \theta, T \mid$.) in Equation (3), we can derive the probability of redistribution $P(p, \theta \mid$.) only as a function of efficacy $p$ and delegitimation $\theta$. This is obtained by plugging the interior solution in (4) into (3) and noting that in the full clientelism regime $P=0$ and in the 'clientelism too expensive' regime, $P=1$ :

$$
P(p, \theta \mid y, \bar{y}, \sigma, g)= \begin{cases}0 & \text { if } \quad p \leq p_{0}(\theta) \\ \frac{1}{2 \sigma}(p+\sigma-(1-\sqrt{B(\theta) 2 \sigma})) & \text { if } \quad p_{0}(\theta)<p \leq p_{1}(\theta) \\ 1 & \text { if } \quad p>p_{1}(\theta)\end{cases}
$$

where $p_{0}(\theta)$ and $p_{1}(\theta)$ are defined previously.

We now turn to the citizens choice of inequality delegitimation. Citizens choose $z$ to maximize $\theta(z)(\bar{y}-y)(\alpha-(1-p))$, where $\theta(z)=\eta \tilde{\theta}+(1-\eta) z$ and with the restriction that $\theta \in[\underline{\theta}, \bar{\theta}]$. Solving this maximization problem immediately implies that

$$
\theta(p \mid .) \in\left\{\begin{array}{cl}
\underline{\theta} & \text { if } p<1-\alpha \\
{[\underline{\theta}, \bar{\theta}]} & \text { if } p=1-\alpha \\
\bar{\theta} & \text { if } p>1-\alpha
\end{array}\right.
$$


The function $\theta(p \mid \alpha)$ depends only on variables and parameters common to the community. This warrants our assertion that all citizens make choices that lead them to the same level of delegitimation and is the reason why we drop the superscript $i$ for the variable $\theta$.

One possible way to finalize the solution of the model from here is to plug $\theta(p \mid$. into $P(p, \theta \mid$.), to obtain $P(p \mid$.), and then apply the rational expectations equilibrium condition $p=P(p \mid$.$) .$

We follow another possible avenue. First, we apply the rational expectations equilibrium condition $p=P(p, \theta \mid$.) to (5), which delivers a condition $p(\theta)$ and then we solve the system of equations formed by this equation, $p(\theta)$, and the equation $\theta(p)$, from the determination of delegitimation in (6).

From here onward, we focus for simplicity on the case where $\sigma=\frac{1}{2}$. Setting $\sigma=\frac{1}{2}$, the probability of redistribution $P(p, \theta \mid$.$) in (5) equals$

$$
P(p, \theta \mid .)= \begin{cases}0 & \text { if } p \leq \frac{1}{2}-\sqrt{B(\theta)} \\ p-\frac{1}{2}+\sqrt{B(\theta)} & \text { if } \frac{1}{2}-\sqrt{B}<p \leq \frac{3}{2}-2 \sqrt{B(\theta)} \\ 1 & \text { if } p>\frac{3}{2}-2 \sqrt{B(\theta)}\end{cases}
$$

The condition $p(\theta)$ that results from applying the equilibrium condition $p=P(p)$ to $P(p, \theta \mid$.) is

$$
p(\theta \mid .)= \begin{cases}\{0\} & \text { if } B(\theta)<\frac{1}{16} \\ \{0,1\} & \text { if } B(\theta) \in\left[\frac{1}{16} \frac{1}{16}\right) \\ \cup\{1\} & \text { if } B(\theta)=\frac{1}{4} \\ \{1\} & \text { if } B(\theta)>\frac{1}{4}\end{cases}
$$

To see this, note that, first, $p(\theta \mid)=$.0 is a fixed point of $P(p, \theta)$ if $\frac{1}{2}-\sqrt{(B)} \geqslant 0$, because then $p=0$ leads to $P=0$. This happens when $B \leq \frac{1}{4}$. Second, the same argument implies that $p(\theta \mid)=$.1 is a fixed point when $B \geqslant \frac{1}{16}$. Third, in the interior regime, when $\frac{1}{2}=\sqrt{B}$ (or, equivalently, $B=\frac{1}{4}$ ), $P$ is always equal to $p$. This regime applies when $\frac{1}{2}-\sqrt{B} \leq p \leq \frac{3}{2}-2 B$ and $B=\frac{1}{4}$, which implies it holds when $p \in\left[0, \frac{1}{2}\right]$.

We now just need to solve the system of equations given by $p(\theta \mid$.$) in (7) and$ $\theta\left(p \mid\right.$.) in (6). Here $p^{*}=0$ implies $\theta^{*}=\underline{\theta}$ in (6) and $\theta^{*}=\underline{\theta}$ in turn implies $p^{*}=0$ in (7) if $B(\underline{\theta}) \leq \frac{1}{4}$, as assumed in the proposition. Therefore, $p^{*}=0$ and $\theta^{*}=\underline{\theta}$ is an equilibrium. Because $p^{*}=0$, the probability of redistribution $P^{*}=0$, and the level of clientelism $C^{*}=1-P^{*}=1$. This is the 'traditional clientelism' equilibrium. The assumption $B(\underline{\theta})<\frac{1}{4}$ thus ensures the existence of the traditional clientelism equilibrium.

By the same argument, $p^{*}=1$ and $\theta^{*}=\bar{\theta}$ are an equilibrium when $B(\bar{\theta}) \geqslant \frac{1}{6}$. Then, the probability of redistribution $P^{*}=1$, and the level of clientelism $C^{*}=1-P^{*}=0$. This is the 'no clientelism' equilibrium.

Finally, $p^{*}=1-\alpha$ is consistent with any value of $\theta$ between $\underline{\theta}$ and $\bar{\theta}$, and $\theta^{*}=\frac{1}{4 g(\bar{y}-y)}-1$ (which makes $B\left(\theta^{*}\right)=\frac{1}{4}$ ) is consistent with any value of $p$ between 0 and $\frac{1}{2}$. The two conditions can hold simultaneously if $\alpha>\frac{1}{2}$ (so that $p^{*}=1-\alpha<\frac{1}{2}$ ) 
and $B(\underline{\theta})<\frac{1}{4}<B(\bar{\theta})$ (so that $B\left(\theta^{*}\right)=\frac{1}{4}$ is feasible). In this equilibrium $P^{*}=1-\alpha$, and $C^{*}=\alpha$. This is the 'modern clientelism' equilibrium.

2. To derive the level of transfers given by the patron in the different equilibria, note the following. The 'traditional clientelism' equilibrium features $P^{*}=0$ and therefore corresponds to the 'full clientelism' regime in (4). The transfers that apply are $\frac{B(\theta)}{1-p-\sigma}$. Once we set the equilibrium values and the assumption that $\sigma=\frac{1}{2}$, this simplifies to $T^{*}=2 B(\underline{\theta})$.

The transfers in the 'modern clientelism' equilibrium are those applying in the interior regime in (4). After setting $\sigma=\frac{1}{2}$, and $B(\theta)=\frac{1}{4}$ they equal $T^{*}=\frac{1}{2}$.

The fact that transfers in the traditional clientelism equilibrium are lower than in the modern one follows directly from comparing $2 B(\underline{\theta})$ and $\frac{1}{2}$. This holds as long as $B(\underline{\theta})<\frac{1}{4}$, which is the assumption that ensures the existence of the 'traditional equilibrium.'

The difference between the transfers in the two regimes can be decomposed into two positive parts, where the subscripts $M$ and $T$ refer to the modern and the traditional equilibrium. Adding and subtracting $\sqrt{B\left(\theta_{T}^{*}\right)}$ yields

$$
\begin{aligned}
T_{M}^{*}-T_{T}^{*}= & \left.\sqrt{B\left(\theta_{M}^{*}\right)}-2 B\left(\theta_{T}^{*}\right)\right) \\
= & \sqrt{B\left(\theta_{M}^{*}\right.}-\sqrt{B\left(\theta_{T}^{*}\right)} \\
& +\sqrt{B\left(\theta_{T}^{*}\right)}-2 B\left(\theta_{T}^{*}\right)
\end{aligned}
$$

This expression decomposes the difference in equilibrium transfers into a part owing to differences in inequality delegitimation $\theta^{*}$ and differences in the functional form linking inequality delegitimation to the patron choice of transfers: in the traditional clientelism equilibrium, the transfer choice is one of the corner solutions, whereas in the modern clientelism equilibrium, it is an interior solution.

The first part is positive because $B\left(\theta_{M}^{*}\right)=\frac{1}{4}>\theta_{T}^{*}=B(\underline{\theta})$ from the assumption ensuring the existence of the 'traditional equilibrium.' This assumption also implies that the second part is positive.

Proof. In each generation $t$, citizens start with given $p_{t}$ and $\theta_{t}$ and decide their transmission of delegitimation $z_{t}$. After the patron has chosen $T_{t}$ and the idiosyncratic efficacy shock $\epsilon_{t}^{i}$ has been realized, they compare the value of $V_{R}$ and $V_{C}$ to decide whether to engage in clientelism or support the redistributive platform. This decision leads to the actual probability of redistribution $P_{t}$.

Comparing expressions (1) and (2) from the static model, with the appropriate time subindices, gives a critical value of efficacy above which people support redistribution. This critical value is the same as in the static model, with appropriate time subindices: $\hat{p}_{t}\left(p_{t}, \theta_{t}, T_{t} \mid.\right) \equiv 1-\frac{B\left(\theta_{t}\right)}{T_{t}}$, where $B\left(\theta_{t}\right) \equiv g(\bar{y}-y)\left(1+\theta_{t}\right)$.

The probability of redistribution $P_{t}\left(p_{t}, \theta_{t}, T_{t}\right)$, given $p_{t}, \theta_{t}$, and $T_{t}$, is then also as in the static model in (3), again with appropriate time subindices. 
The patron decision of $T_{t}$ is also the same as in the static model, and given by (4), again with appropriate time subindices.

Therefore, the probability of redistribution accounting for the patron choice $P_{t}\left(p_{t}, \theta_{t} \mid.\right)$ is also as in the static model, given by (5).

According to the assumptions of the dynamic model, benchmark efficacy of generation $t+1$ equals the actual probability of redistribution at time $t: p_{t+1}=P_{t}$. As $P_{t}\left(p_{t}, \theta_{t} \mid.\right)$ depends on benchmark efficacy in generation $t, p_{t}$, this equality leads to an equation in differences governing the dynamics of $p_{t}$, given $\theta_{t}$. Therefore, replacing $P$ for $p_{t+1}$, and adding the corresponding time subindices in (5) yields

$$
p_{t+1}\left(p_{t}, \theta_{t} \mid .\right)= \begin{cases}0 & \text { if } p_{t} \leq p_{0}\left(\theta_{t}\right) \\ \frac{1}{2 \sigma}\left(p_{t}+\sigma-\left(1-\sqrt{B\left(\theta_{t}\right) 2 \sigma}\right)\right) & \text { if } p_{0}\left(\theta_{t}\right)<p_{t} \leq p_{1}\left(\theta_{t}\right) \\ 1 & \text { if } p_{t}>p_{1}\left(\theta_{t}\right)\end{cases}
$$

where $p_{0}\left(\theta_{t}\right)$ and $p_{1}\left(\theta_{t}\right)$ are given in the proof of Proposition 1 .

For given $\theta_{t}$, dynamics are explosive if $\frac{\delta p_{t+1}}{\delta p_{t}}>1$, and this occurs when $\sigma<\frac{1}{2}$.

We now consider the choice of $z_{t}$ and the consequent determination of $\theta_{t+1}$. Parents choose $z_{t}$ to maximize (9). Taking the first-order condition of this expression yields the choice of $z_{t}$ as a function of delegitimation and efficacy beliefs of generation $t$ :

$$
z_{t}\left(\theta_{t}, p_{t} \mid .\right)=\theta_{t}+(1-\eta)(\bar{y}-y)\left(p_{t}-(1-\alpha)\right)
$$

Because delegitimation beliefs of generation $t+1$ depend only on $z_{t}\left(\theta_{t}, p_{t} \mid.\right)$ and on parameters, plugging the expression for $z_{t}$ expression into expression (8), we obtain $\theta_{t+1}\left(\theta_{t}, p_{t} \mid.\right)$ :

$$
\theta_{t+1}\left(p_{t}, \theta_{t} \mid .\right)=\eta \tilde{\theta}+(1-\eta) \theta_{t}+(1-\eta)^{2}(\bar{y}-y)\left(p_{t}-(1-\alpha)\right)
$$

The equations in differences (11) and (10), together with the initial conditions $p_{0}$ and $\theta_{0}$, and the myopic choice $T_{t}$ (given in (4) with the corresponding time subindices), characterize the dynamics of model: for given $p_{0}$ and $\theta_{0}, T_{1}$ is given by (4), $p_{1}$ is given by (10), $\theta_{1}$ is given by (11), and so on.

From here onwards, we provide an informal proof of the proposition using a phase diagram. We start by constructing the schedules that keep $p$ and $\theta$ constant, respectively, in the $(\theta, p)$ space. The one for $\theta(\Delta \theta=0)$ follows directly from subtracting $\theta_{t}$ from both sides of (11), setting it to zero and solving for $p_{t}$. We denote it as $p_{\theta}\left(\theta_{t}\right)$, with a subscript $\theta$, to make clear that it is the level of $p$ that makes $\theta$ constant:

$$
\Delta \theta=0 \rightarrow p_{\theta, t}\left(\theta_{t}\right)=(1-\alpha)+\frac{\eta}{(1-\eta)^{2}} \frac{1}{\bar{y}-y}\left(\theta_{t}-\tilde{\theta}\right)
$$

The schedule for $p(\Delta p=0)$ follows from (10), by subtracting $p_{t}$ from $p_{t+1}$, and setting the expressions to zero. This yields 

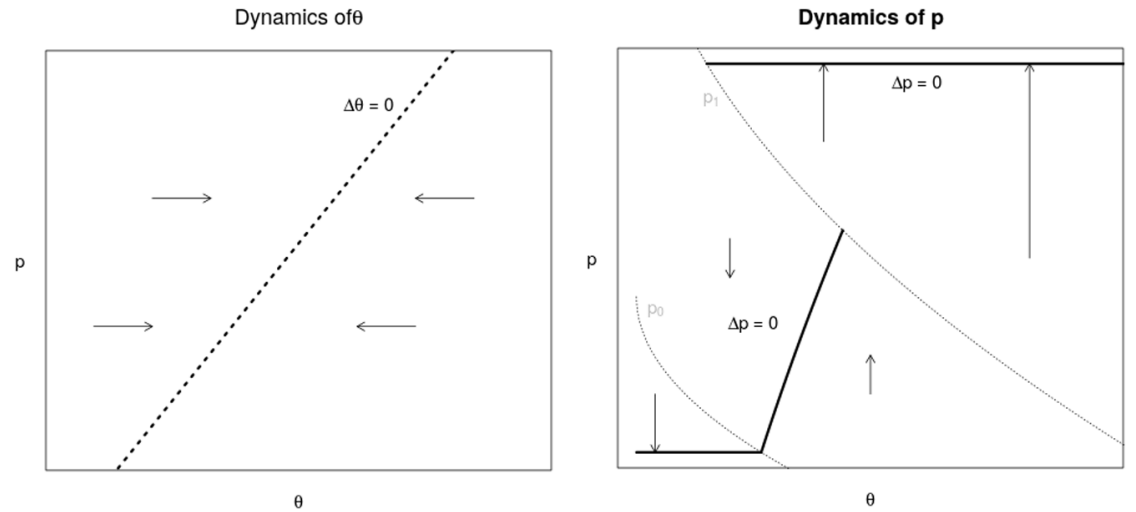

Figure AI. Dynamics of $p_{t}$ and of $\theta_{t}$.

$$
\Delta p=0 \rightarrow p_{t}\left(\theta_{t}\right)= \begin{cases}0 & \text { if } 0 \leq p_{0}\left(\theta_{t}\right) \\ p_{\text {int }}\left(\theta_{t}\right) & \text { if } p_{0}(\theta)<p_{\text {int }}\left(\theta_{t}\right) \leq p_{1}\left(\theta_{t}\right) \\ 1 & \text { if } 1>p_{1}\left(\theta_{t}\right)\end{cases}
$$

where $p_{\text {int }}(\theta) \equiv \frac{\sigma+\sqrt{B\left(\theta_{t}\right) 2 \sigma}-1}{2 \sigma-1}, p_{0}\left(\theta_{t}\right) \equiv 1-\sigma-\sqrt{B\left(\theta_{t}\right) 2 \sigma}$, and $p_{1}\left(\theta_{t}\right) \equiv 1+\sigma-2$ $\sqrt{B\left(\theta_{t}\right) 2 \sigma}$.

These schedules can be used to construct a phase diagram depicting the dynamics of the system. It is straightforward to see that the $\Delta \theta=0$ schedule is increasing in $\theta_{t}$, so it slopes upward in the $(\theta, p)$ space. It is also plain that this slope is increasing in $\eta$. As $\eta$ goes to zero the schedule becomes flat and when $\eta$ goes to one, the schedule becomes vertical. The dynamics are also easy to derive from (11). If $p_{t}$ is higher than $p_{\theta}\left(\theta_{t}\right), \theta_{t}$ increases, and vice versa. The left panel of Figure A1 illustrates this.

The $\Delta p=0$ schedule is the same as the schedule for $p(\theta)$ in the static model, except that $\sigma$ is allowed to be free. Thus, the schedule has three parts, corresponding to the different patron transfers regimes. The schedule is flat at zero if $p_{0}\left(\theta_{t}\right) \leq 0\left(\theta_{t}\right.$ is sufficiently low $)$, flat at one if $p_{1}\left(\theta_{t}\right)<1\left(\theta_{t}\right.$ is sufficiently high), and $p_{\text {int }}\left(\theta_{t}\right)$ corresponding to the interior regime otherwise.

Allowing $\sigma$ to be free has implications mainly for the interior regime: in the static equilibrium, $p(\theta)$ was vertical, but now the schedule can slope upwards or downwards, depending on $\sigma$. It is clear from the expression for $\Delta p=0$ that $p_{\text {int }}\left(\theta_{t}\right)$ is vertical if $\sigma=\frac{1}{2}$, positively sloped if $\sigma>\frac{1}{2}$ and negatively sloped otherwise.

To further characterize the schedule, note that its derivative relative to $B(\theta)$ equals

$$
\frac{\sqrt{2 \sigma}}{2 \sqrt{B}(2 \sigma-1)}
$$




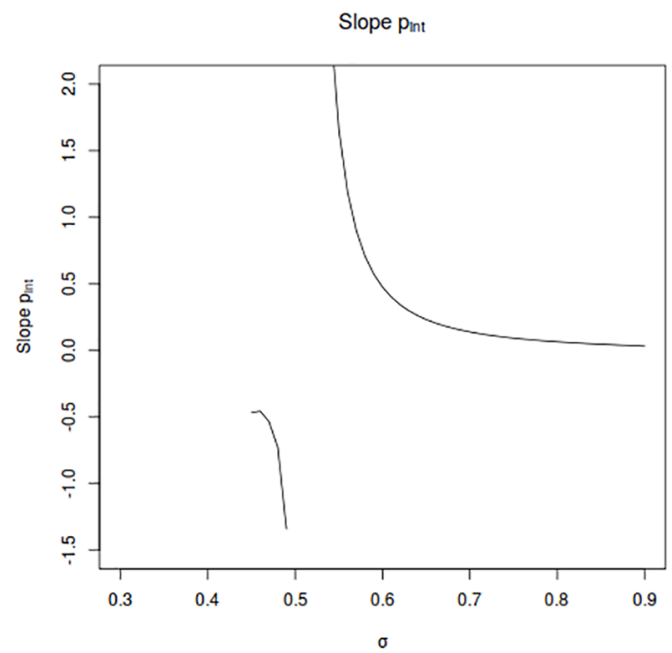

Figure A2. Slope of $p_{\text {int }}$ with respect to $\sigma$ evaluated at the interior $\theta$ steady state.

It is easy to show that this expression is decreasing in $\sigma$ (except in the discontinuity at $\sigma=\frac{1}{2}$ ). Moreover, this expression tends to zero when sigma tends towards infinity. Putting these results together implies that $p_{\text {int }}\left(\theta_{t}\right)$ has a negative slope when $\sigma$ is low, and rotates clockwise as $\sigma$ increases, first becoming vertical at $\sigma=\frac{1}{2}$ and eventually becoming flat when $\sigma \rightarrow \infty$.

The dynamics of $p_{t}$ can be easily derived from (10): $p_{t}$ goes directly to zero if $p_{t} \leq p_{0}\left(\theta_{t}\right)$ and goes directly to one if $p_{t}>p_{1}\left(\theta_{t}\right)$. Otherwise, dynamics are dictated by the interior regime in (10). These imply that if $\theta_{t}$ is higher than $p_{\text {int }}\left(\theta_{t}\right)$ (i.e., to the right in the $(\theta, p)$ space), $p_{t}$ increases, and vice versa. The right panel of Figure A1 illustrates this, for $\sigma=0.6$.

Putting together the dynamics of $\theta_{t}$ and those of $p_{t}$ makes it immediately apparent that the dynamics of the system depend on which of the two schedules $\left(p_{\text {int }}\left(\theta_{t}\right)\right.$ or $\left.p_{\theta}\left(\theta_{t}\right)\right)$ has a higher slope at the point where the two lines intercept (the corresponding steady-state value of $\theta$ and $p$ ).

The results in the proposition follow by noting from the discussion before that $p_{\theta}$ rotates anti-clockwise from zero to infinity as $\eta$ goes from zero to one, whereas $p_{\text {int }}$ rotates clockwise as $\sigma$ increases (from negative if $\sigma<\frac{1}{2}$, to vertical if $\sigma=\frac{1}{2}$, to flat if $\sigma \rightarrow \infty)$. Therefore, $p_{\theta}$ has a steeper slope than $p_{\text {int }}$ when $\sigma$ and $\eta$ are above some threshold, and vice versa. This discussion, however, does not take into consideration that the slope of $p_{\text {int }}$ depends on $\theta$, and that the steady-state level of $\theta$ itself depends on $\sigma$. The parameter $\sigma$ affects the slope of $p_{\text {int }}$ evaluated at the steady-state level of $\theta$ also through its effect on the steady-state level of $\theta$. It is difficult to provide a general proof that, even taking this into consideration, $p_{\text {int }}$ still rotates clockwise as $\sigma$ increases as mentioned previously. We provide here an informal graphical illustration of the result, using 'sensible' parameter values in Figure A2. ${ }^{11}$ 


\section{Notes}

1. This is a vast literature. For reviews, see Hicken (2011) and Mares and Young (2016).

2. One may consider that the rich patron stands for a rich family with income $y^{R}$ that has a small associated measure $\phi$ so that $\bar{y}=\frac{y+\phi y^{R}}{1+\phi}$.

3 . The $i$ appears as a superscript in order to allow for the subscript $t$ (denoting generations) in the dynamic extension of the model in the following.

4. We assume that the citizen's inequality delegitimation choice and the patron transfer choice is simultaneous for simplicity, because it implies that neither of the two choices is done foreseeing the consequences of the choice for the other actor

5. The work of Major and Schmader (2001) contrasts two opposing social psychology theories on the self-esteem implications of delegitimizing inequality. 'Ego defense perspectives' argue that perceiving social inequalities as unjust can be protective emotionally, as this buffers self-esteem by over-attributing personal bad outcomes to external factors such as discrimination and injustice. 'System justification' theories, in contrast, argue that consistently believing in an unfair world erodes self-esteem. The argument is that beliefs in an unjust world erodes the feeling of being socially accepted, or generates anxiety by decreasing one's perception of predictability and control over the environment.

6. With 'true' value we mean an objective measure of how much incomes are generated according to standard conceptions of justice, such as the degree of equality of opportunity or whether incomes are obtained through effort versus connections.

7. The formulation of delegitimation belief as partly chosen and partly given by the reality of their environment does not really play a role in the static model, but it will be relevant in the dynamic extension in the following.

8. The results in the proposition are for the case where $\sigma=\frac{1}{2}$ because otherwise corner solutions make the full characterization of the equilibrium cumbersome. Most derivations in the proof, however, are done allowing $\sigma$ to be a free parameter. The following dynamic model also allows $\sigma$ to be a free parameter.

9. As in the static model, all citizens in a given generation make the same choices regarding their children's delegitimation beliefs and so we drop the superscript $i$ in $\theta_{t}^{i}$.

10. As for $\theta$, all citizens in a given generation make the same choices $z_{t}$ and so we drop the superscript $i$.

11. The parameter values are $\eta=0.6, \alpha=0.7, g=0.01,(\bar{y}-y)=10$, and $\tilde{\theta}=0.35$.

12. An important exception is Bustikova and Corduneanu-Huci (2017) who focus on trust as a factor in the decline of clientelism.

\section{References}

Acharya A, Blackwell M and Sen M (2018) Explaining preferences from behavior: A cognitive dissonance approach. The Journal of Politics 80: 2.

Aidt TS and Jensen PS (2017) From open to secret ballot: Vote buying and modernization. Comparative Political Studies 50(5): 555-593.

Alesina A and Giuliano P (2011) Preferences for redistribution. In: Heffetz O, Frank RH, Benhabib J, Bisin A and Jackson M (eds.) Handbook of Social Economics. Amsterdam: North-Holland, pp. 93-132.

Alesina A and La Ferrara E (2005) Preferences for redistribution in the land of opportunities. Journal of Public Economics 89(5-6): 897-931. 
Archer RP (1990) The transition from traditional to broker clientelism in Colombia: Political stability and social unrest. Kellog Institute Working Paper 140 (July).

Arghiros D (2001) Democracy, Development and Decentralization in Provincial Thailand. Curzon Press.

Auyero J (1999) From the client's point(s) of view: How poor people perceive and evaluate political clientelism. Theory and Society 28(2): 297-334.

Auyero J (2000) The logic of clientelism in Argentina: An ethnographic account. Latin American research review 35(3): 55-81.

Becerra Mizuno EL (2013) Does Everyone Have a Price? The Demand Side of Clientelism and Vote-Buying in an Emerging Democracy. $\mathrm{PhD}$ Thesis, Duke University.

Benabou R and Tirole $\mathrm{J}$ (2006) Belief in a just world and redistributive politics. The Quarterly Journal of Economics 121(2): 699-746.

Brusco V, Nazareno M and Stokes S (2004) Vote buying in Argentina. Latin American Research Review 39(2): 66-88.

Bustikova L and Corduneanu-Huci C (2017) Patronage, trust, and state capacity: The historical trajectories of clientelism. World Politics 69(2): 277-326.

Corstange D (2018) Clientelism in competitive and uncompetitive elections. Comparative Political Studies 51(1): 76-104.

Dixit A and Londregan J (1996) The determinants of success of special interests in redistributive politics. Journal of Politics 58: 1132-1155.

Duckitt J and Sibley CG (2010) Personality, ideology, prejudice, and politics: A dual-process motivational model. Journal of Personality 78(6): 1861-1894.

Fernández PD, Mart I and Farchi T (2017) Mundane and everyday politics for and from the neighborhood. Organization Studies 38(2): 201-223.

Finan F and Schechter L (2012) Vote-buying and reciprocity. Econometrica 80(2): 863-881.

Foltz WJ (1969) Social structure and political behavior of senegalese elites. Cross-Cultural Research 4(2): 145-163.

Gallego J (2015) Self-enforcing clientelism. Journal of Theoretical Politics 27(3): 401-427.

Gans-Morse J, Mazzuca S and Nichter S (2014) Varieties of clientelism: Machine politics during elections. American Journal of Political Science 58(2): 415-432.

Gay R (1998) Rethinking clientelism: demands, discourses and practices in contemporary brazil. Revista Europea de Estudios Latinoamericanos y del Caribe/European Review of Latin American and Caribbean Studies 65: 7-24.

Gonzalez-Acosta E (2008) Dominican Republic - Political clientelism and poverty. AlterInfos. Available at: http://alterinfos.org/spip.php?article2001.

Gottlieb J (2017) Explaining variation in broker strategies: A lab-in-the-field experiment in Senegal. Comparative Political Studies 50(11): 1556-1592.

Hicken A (2011) Clientelism. Annual Review of Political Science 14: 289-310.

Hilgers T (2009) 'Who is using whom?' Clientelism from the client's perspective. Journal of Iberian and Latin American Research 15(1): 51-75.

Hilgers T (2012) Clientelism in Everyday Latin American Politics. New York: Palgrave Macmillan.

Holzner C (2004) The end of clientelism? Strong and weak networks in a mexican squatter movement. Mobilization: An International Quarterly 9(3): 223-240.

Johnson IR and Fujita K (2012) Change we can believe in using perceptions of changeability to promote system-change motives over system-justification motives in information search. Psychological Science 23(2): 133-140. 
Jost JT, Banaji MR and Nosek BA (2004) A decade of system justification theory: Accumulated evidence of conscious and unconscious bolstering of the status quo. Political Psychology 25(6): 881-919.

Jost JT, Chaikalis-Petritsis V, Abrams D, Sidanius J, Van Der Toorn J and Bratt C (2012) Why men (and women) do and don't rebel. Effects of system justification on willingness to protest. Personality and Social Psychology Bulletin 38(2): 197-208.

Jost JT, Glaser J, Kruglanski AW and Sulloway FJ (2003) Political conservatism as motivated social cognition. Psychological Bulletin 129(3): 339.

Justesen MK and Manzetti P Luigi (2017) Poverty, partisanship and vote buying DOI: $10.2139 /$ ssrn.2902515.

Kay AC and Friesen J (2011) On social stability and social change understanding when system justification does and does not occur. Current Directions in Psychological Science 20(6): 360-364.

Keefer P and Vlaicu R (2008) Democracy, credibility, and clientelism. Journal of Law, Economics, and Organization 24(2): 371-406.

Kitschelt H and Kselman DM (2013) Economic development, democratic experience, and political parties' linkage strategies. Comparative Political Studies 46(11): 1453-1484.

Kramon E (2016) Electoral handouts as information: Explaining unmonitored vote buying. World Politics 68(3): 454-498.

Kramon E (2017) Money for Votes: The Causes and Consequences of Electoral Clientelism in Africa. Cambridge: Cambridge University Press.

Landé CH (1977) Introduction: The dyadic basis of clientelism. In: Schmidt S, Guasti L, Landé C and Scott J (eds.) Friends, Followers, and Factions: A Reader in Political Clientelism. Berkeley, CA: UC Press, pp. XIII-XXXVII.

Lawson C and Greene KF (2014) Making clientelism work: How norms of reciprocity increase voter compliance. Comparative Politics 47(1): 61-85.

Lazar S (2004) Personalist politics, clientelism and citizenship: Local elections in El Alto, Bolivia. Bulletin of Latin American Research 23(2): 228-243.

Lemarchand R (1972) Political clientelism and ethnicity in tropical Africa: Competing solidarities in nation-building. American Political Science Review 66(01): 68-90.

Lerner MJ (1982) The Belief in a Just World: A Fundamental Delusion. New York: Plenum Press.

Major B and Schmader T (2001) Legitimacy and the construal of social disadvantage. In: Jost JT and Major B (eds.) The Psychology of Legitimacy. Cambridge: Cambridge University Press, pp. 176-204.

Mares I and Young L (2016) Buying, expropriating, and stealing votes. Annual Review of Political Science 19: 267-288.

Meltzer AH and Richard SF (1981) A rational theory of the size of government. Journal of Political Economy 89(6): 914-927.

Minozzi W (2013) Endogenous beliefs in models of politics. American Journal of Political Science 57(3): 566-581.

Mitlin D and Mogaladi J (2013) Social movements and the struggle for shelter: A case study of Ethekwini (Durban). Progress in Planning 84: 1-39.

Nichter S (2014) Conceptualizing vote buying. Electoral Studies 35: 315-327.

Nichter S (2018) Votes for survival: Relational clientelism in Latin America. Cambridge: Cambridge University Press.

Nichter S and Peress M (2017) Request fulfilling: When citizens demand clientelist benefits. Comparative Political Studies 50(8): 1086-1117. 
Paller JW (2014) Informal institutions and personal rule in urban Ghana. African Studies Review 57(3): 123-142.

Pellicer M, Piraino P and Wegner E (2018) Perceptions of inevitability and demand for redistribution: Evidence from a survey experiment. Journal of Economic Behavior and Organization 159: 274-288.

Pellicer M, Wegner E, Bayer M and Tischmeyer C (2020) Clientelism from the client's perspective: A meta-analysis of ethnographic literature. Perspectives on Politics. DOI: $10.1017 /$ S153759272000420X.

Pellicer M, Wegner E and De Juan A (2019) Preferences for the scope of protests. Political Research Quarterly. DOI: 10.1177/1065912920905001.

Powell JD (1970) Peasant society and clientelist politics. American Political Science Review 64(02): 411-425.

Robinson JA and Verdier T (2013) The political economy of clientelism. The Scandinavian Journal of Economics 115(2): 260-291.

Rutten R (2007) Losing face in philippine labor confrontations: How shame may Inhibit worker activism. In: New Perspectives in Political Ethnography. Berlin: Springer, pp. 3759.

Schmidt S, Guasti L, Landé C and Scott J (eds.) (1977) Friends, Followers, and Factions: A Reader in Political Clientelism. Berkeley, CA: UC Press.

Scott JC (1972) Patron-client politics and political change in Southeast Asia. American Political Science Review 66(1): 91-113.

Shami M (2012) Collective action, clientelism, and connectivity. American Political Science Review 106(3): 588-606.

Shefner J (2001) Coalitions and clientelism in Mexico. Theory and Society 30(5): 593-628.

Silverman S (1977) Patronage and community - Nation relationships in Central Italy. In: Schmidt S, Guasti L, Landé C and Scott J (eds.) Friends, Followers, and Factions: A Reader in Political Clientelism. Berkeley, CA: UC Press, pp. 293-304.

Stokes S (2005) Perverse accountability: A formal model of machine politics with evidence from Argentina. American Political Science Review 99(3): 315-325.

Stokes S, Dunning T, Nazareno M and Brusco V (2013) Brokers, Voters, and Clientelism: The Puzzle of Distributive Politics. Cambridge: Cambridge University Press.

Svampa M and Pereyra S (2009) Entre la ruta y el barrio: la experiencia de las organizaciones piqueteras. Editorial Biblos.

Thompson EP (1963) The Making of the English Working Class. Victor Gollancz Ltd.

Van der Toorn J, Feinberg M, Jost JT, et al. (2015) A sense of powerlessness fosters system justification. Political Psychology 36(1): 93-110.

Van Zomeren M, Postmes T and Spears R (2008) Toward an integrative social identity model of collective action: A quantitative research synthesis of three socio-psychological perspectives. Psychological bulletin 134(4): 504-535.

Weingrod A (1968) Patrons, patronage, and political parties. Comparative Studies in Society and History 10(4): 377-400. 